\title{
The Ethics of Health Promotion: From Public Health to Health Care
}

\author{
Berge Solberg
}

\section{Abstract}

Health promotion is often been associated with altering social arrangement in order to improve the health of citizens - the domain of public health. Ethical aspects of health promotion then is generally discussed in terms of a public health ethics. In this chapter, I start out with some classical ethical and political dilemmas of health promotion in public health before I move into the ethics of health promotion in health care. I argue that empowerment, better than any other value, may serve as the ethical foundation for health promotion in health care. I further claim that empowerment may serve as the ethical bridge between health promotion in health care and health promotion in public health.

\section{Keywords}

Ethics $\cdot$ Empowerment $\cdot$ Autonomy Paternalism $\cdot$ Nudging $\cdot$ Health $\cdot$ Positive freedom $\cdot$ Salutogenesis $\cdot$ Agency
B. Solberg $(\bowtie)$

Department of Public Health and Nursing, The Norwegian University of Science and Technology (NTNU), Trondheim, Norway

e-mail: berge.solberg@ntnu.no

\subsection{Introduction}

Even though 'health promotion' probably has been defined again and again in this book, we still need to pay attention to the definition before we start talking about ethics. 'Health promotion is the process of enabling people to increase control over, and to improve, their health. To reach a state of complete physical, mental and social wellbeing, an individual or group must be able to identify and to realize aspirations, to satisfy needs, and to change or cope with the environment'. These are some of the first sentences in the Ottawa charter for Health Promotion from 1986 [1]. Taken in isolation, they may suggest that health promotion mainly has to do with the wellbeing of individual persons and patients. If that is the case, an ethics of health promotion seems to be some variants of an ethics of health care.

If we, however, focus on the first sentence of the charter, we can notice that it says that 'this conference was primarily a response to growing expectations for a new public health movement around the world'. Health promotion is here associated with public health. In a paper with the telling title How to Think about Health Promotion Ethics, Carter et al. define an ethics of health promotion in this way: 'We consider the normative ideal of health promotion to be that aspect of public health practice that is particularly concerned with the equity of social arrangements: it imagines that social arrangements can be altered 
to make things better for everyone, whatever their health risks, and seeks to achieve this in collaboration with citizens. This raises two main ethical questions. First: what is a good society? And then: what should health promotion contribute to a good society?' [2]. If they are correct, an ethics of health promotion seems to be some variants of an ethics of public health.

An ethics of health promotion belongs to both spheres. In many ethical discussions, public health has been a natural framework. The ethical questions are clearly recognizable on this arena. But already in the Ottawa charter, there is a call for reorienting the health services in the direction of health promotion. In this chapter, we take a roundabout way. We start with some basic concepts of political philosophy that gives us a framework for the discussion. Then we take a look at some of the typical ethical dilemmas of health promotion in public health, before we end up with articulating an ethics of health promotion within health care.

\subsection{The Two Concepts of Liberty: Two Concepts of Health?}

A deep discussion on the ethical justifiability of health promotion in a society needs to start with some considerations on the relation between the individual and the society. A person's view on the legitimacy and the need for health promotion will very often reflect his political position. Both libertarians and communitarians will be concerned with freedom and choice, but different concepts of freedom will be applied. For libertarians, only freedom from an intrusive and paternalistic state will be genuine freedom. For communitarians, only freedom to realize your potential will amount to genuine freedom. These are the "two concepts of liberty' that Isaiah Berlin talked about in his famous paper from 1958 [3].

Negative freedom means that you are free, as long as you are left to do whatever you want to do without interference from others (except from harming other people). The more other people, the society and the state interfere with your life, the less freedom you have. Low taxes give you more freedom than high taxes, because the former interferes less with your life than the latter. Individuality and liberty must be protected from the community. Negative freedom is often referred to as 'freedom from...'.

Positive freedom means the freedom to pursue and realize your interest and priorities in your life. If I am really interested in an academic career, but cannot afford education, then my freedom is limited, even though the state has not interfered with my wishes. Rather the opposite would be true; the fact that the state has not provided opportunities for free education makes me less free than I could have been. Defenders of positive freedom very often argue that the negative concept of liberty is naive and insufficient [4]. Positive freedom is the rationale for the welfare state and the idea that everybody should have equal opportunity to participate in the different practices of a society. The focus is very often systemic: Individuality and liberty are dependent on a strong community. Positive freedom is often referred to as 'freedom to...'.

The positive concept of liberty has substantial resemblance with the concept of health applauded in health promotion. Central in the theory of health promotion is the term salutogenesis, coined by Aaron Antonovsky [5], where he saw the origins of health in the factors causing wellbeing and meaning. While health understood as the absence of disease would amount to a negative understanding of health, health understood in the tradition of health promotion is a positive one. Like positive liberty, health is here understood as a concept of realization and capabilities: It means being able to realize a biological potential, realize aspirations, to satisfy needs and to change or cope with the environment-again to quote the Ottawa charter.

In the same way that there exist two fundamentally different concepts of liberty, it seems fair to claim that there exist two fundamentally different concepts of health. Health promotion is based on a positive concept, where health, like freedom, is something that can be realized given the proper context. The positive concept of health, like the positive concept of liberty, stresses the importance of others for the individual's real- 
ization of his or her potential. This brings us onto some reflections on the relation between health and responsibility.

\subsection{Poor Health and Responsibility}

In a libertarian model, the individual should be free to make good or bad health choices. Knowledge, attitudes, will power, character, values, habits and more are factors that affect the decision individuals take. These are factors that we think we should be held responsible for. On that background, we are responsible for the health choices we make. To hold individuals responsible for their actions is of intrinsic value-it is the fundamental prerequisite for treating people as autonomous individuals.

At the same time, we know, as a fact, that the society has a huge impact on the individual's health. Access to clean water, sanitation facilities, safe housing, vaccines and a good health care system are of course basic elements in the public health of a society, but the social elements of health go far beyond this. The way a society is politically 'rigged' determines in a deep sense the health of its inhabitants. Education and income are the most prominent social determinants of health [6]. A society with small social inequalities produces healthier individuals than a society with large social inequalities. The more a society manage to distribute education and income in an egalitarian way (where people are treated as equals), the better the health of its citizen will be. In the same way, adverse experiences in a person's biography, like sexual child abuse, seem to be a life-course social determinant of adult health [7]. In this explanation of good and poor health, individual character and will power play a minor role. The social structure as well as the social context of upbringing and socialization plays a major role. Politics plays a major role.

The danger of the libertarian model is that health is 'individualized'. The true social determinants of health are masked by an ideology that says that everything starts and ends with the will of the individual. The danger of the communitar- ian model is that health is 'socialized'. Individual responsibility disappears, autonomy disappears, and individuals in poor health are 'victimized'they are regarded as victims of an unfair society.

Luckily, we do not have to choose between the libertarian and the communitarian model. There are insights from both of them in the salutogenic model of health. A central concept in the salutogenic model of health is sense of coherence. How healthy we feel and how healthy choices we make depend to a certain degree on whether we regard the hardships of our lives as comprehensible, manageable and meaningful [8]. Social context plus individual agency are both inescapable in this model.

\subsection{Health Choices: What Interference Is Ethically Justified?}

The most typical ethical dilemma in public health ethics is that of state interference in choices concerning the health of people. According to the theory of negative liberty, it is of highest value that the state does not interfere with the freedom of people. People should be left alone.

However, from a positive concept of liberty and health-what Carter et al. denote as a capability point of view -interference could be justified. Peoples' most important interest is probably not to be left alone, because ' ...they have a moral stake in that environment providing them with real opportunities, including the opportunity to be healthy' [2].

Informing people through public health campaigns is one of the most classical ways of trying to help people taking good and healthy choices. There is nothing inherently unethical with information campaigns, if the information given is honest and correct. But one problem with them is that results are moderate, probably because education programmes have often failed to acknowledge the limitations of health education or the complex relationship between health communication and behaviour change, according to Gill and Boylan [9]. In order to make them more effective, there is a temptation to move beyond 
factual and objective information and use instruments that make a strong appeal to emotions, like for instance the use of fear and disgust in antitobacco campaigns. While this may have a bigger effect than information, it also increases the risk of stigmatization. As Lupton claims, there is a substantial risk that such campaigns may ' ... reinforce negative attitudes towards already disadvantaged and marginalized individuals and social groups' [10].

A less stigmatizing but maybe more coercive way of trying to improve public health is to tax products that contribute to poor health and disease, like tobacco, alcohol, sugar and fat. Such taxation might contribute to more 'real opportunities' for people to choose healthy, in the sense that unhealthy choices will not continue to be a cheap option. The coercive element here is that if you put really high taxes on some products, it will be too expensive for people to buy regularly.

An even more coercive strategy is to ban certain products or ban the use of certain products. Many countries today have a law on smoking, where smoking is banned in public buildings and transportation, restaurants, offices, etc. Systematic reviews suggest a considerable medical benefit from such legislation $[11,12]$. There are many practical challenges with taxation of as well as a ban on certain products, such as equal treatment of different products and the risk of increased trade leakage to more liberal jurisdictions nearby. But deeper than that is the challenge that we cannot necessarily ban everything we may find unhealthy from our society. The characteristics of a liberal societies is that we allow people to choose the way they will live their lives, as long as this freedom of choice do not harm others, or significantly reduce others freedom of choice. This freedom of choice is regarded as an intrinsic value and as a common good in liberal democracies. A totalitarian regime could easily ban tobacco, Happy Meal, Toblerone and alcohol. But in liberal democracies, such laws would be considered a violation of some of our dearest values. This creates a tension between values. You have to carefully balance the two.
But how could laws against smoking in public indoor areas be introduced in liberal democracies if it violated fundamental liberal values? The answer is that these laws were introduced in the first place to safeguard the work environment. Nobody should be a victim of 'passive smoking'. The justification of these laws was not that health trumped freedom of choice, but rather that the choice of smokers to smoke, threatened the freedom of choice of others (the choice of not smoking/not inhaling nicotine) in these buildings. In that sense, freedom of choice was the justification for banning the freedom to smoke indoors. The paradox, however, is that even though these laws were not motivated by health promotion, the consequences have probably been huge in terms of health.

Some scholars do, however, defend coercive strategies in a liberal democracy. Sarah Conley is one of them. People are generally prone to cognitive bias, says Conley. We make bad decisions because we are tempted, we lack will power and we have a bad means-end thinking. That makes it hard for us to reach our ultimate goals. Coercing people to do what is good for them is in this sense is respectful, because people then will reach their ultimate goals [13].

Is Conley's position compatible with a health promotion view? On the one hand, health promotion is based on empowering and enabling people to realize their health potential. Coercion and prohibitions do not seem to have a place here. On the other hand, some types of addiction may be so hard to ignore and overcome that prohibitions ('you are not allowed to smoke here') actually could be the only thing that may help a person resist the craving for a cigarette. From such a perspective, law limiting and prohibiting smoking may help a person to get in control and in charge of his or her health. Although bans and prohibitions seldom would have a place within the paradigm of health promotion, we cannot absolutely rule out that such strategies may play a role in empowering and enabling people to live the lives that they really want to live.

Conley's position, though, is challenging from a liberal perspective. As Jonathan Pugh has argued that it would be very problematic if it 
becomes impossible for agents to choose some action that poses a risk to their health without them being accused of making a cognitive error in weighing their values [14]. Are all smokers today making a cognitive error when they choose to smoke? Could we ban smoking in general on the assumption that the ultimate goal of all smokers is to quit smoking? Probably the answer is no. People have different values and people weigh their values differently. That means that some smokers have no ultimate goal of quitting smoking. For them, coercive paternalism will become highly illiberal and not enabling them to live more in accordance with ultimate goals and values.

\subsection{Promoting Health Without Taking Away Choices}

An increasingly popular strategy for promoting healthy choices is 'nudging'. Nudging or 'friendly pushing' is, according to Thaler and Sunstein, about changing the choice architecture [15]. No choices will be taken from you, no one will be coerced, nothing will be prohibited, but the choices will look a little bit different than before. When choices are nudged, they have been designed in order to raise the likelihood that you make the good choice. In a friendly way, you are pushed in the direction of what is good for you.

A simple example of nudging is to place fruit and vegetables in the middle of where you enter the groceries store. This makes it impossible to get into the store without feeling the call of buying fruits and vegetables. You still have the freedom to choose not to buy these healthy products, but it is more difficult to drop it, compared to a choice architecture where vegetables and fruit are hidden at the very back wall of the store.

Nudging can be scaled up to include more fundamental aspects of health. In cities, we can take some of the driving lanes and transform them to bike-cycle lanes. This will probably create more cyclists and less drivers and contribute to better health, better environment and less traffic. Still, no choices are removed. You can take your car and drive to work if you prefer that. But, the choice of driving to work is not that attractive anymore while the choice of cycling to work has become much more attractive. You have been nudged towards cycling.

Nudging can be even more scaled up. Urban planning can be done with health promotion as a central perspective. A typical example is socalled age-friendly cities and communities where it is easy to participate when you age, easy to stay connected, stay healthy as well as to receive adequate support. The goal is to 'promote healthy and active ageing and a good quality of life for their older residents' [16]. In such cities, no choice is taken away from you (you can still choose not to participate), but the good choices are much easier and more attractive to make, compared with other cities. When you live in such a city, you will be nudged towards active participating, regularly exercising, healthy food, healthy transportation and healthy work environment-all these will be options that represent more attractive choices than the unhealthy ones.

\subsection{Is Nudging Ethical from a Health Promotion View?}

Nudging could be an effective mean to improve personal as well as public health. There are, however, two typical objections: First, nudging can be accused for being essentially paternalistic. Second, nudging can be accused for being essentially manipulative. If these accusations are valid, nudging seems to be a bad strategy for health promotion.

Paternalism (from Latin pater $=$ father) means that somebody else (a father figure) knows what is good for you. Medical paternalism is an example of something we today consider as an ethical problem because we think that the patient knows best what is good for him or her. Nudging in health promotion presupposes that somebody knows what is best for you and organizes the possible choices in such a way that you will make the 'right' choice. Clearly there is a paternalist element in this, in the same way that coercive strategies for health promotion are paternalistic. In 
addition, the paternalism is partly hidden. That makes nudges more problematic than coercive strategies, where the paternalism is open for everybody to see.

At the same time, it is important to note that choice is not abandoned. We are still within the liberal zone. This is why nudging has been labelled 'liberal paternalism'. Whether paternalism in a given situation is acceptable or problematic depends on whether a certain good is commonly shared, or rather a contested good. Good candidates for nudging presuppose high agreement. To nudge people to eat more fruits and vegetables is not very controversial. There is a general agreement in the society that eating more fruits and vegetables is good for us. To nudge people to read more in the Bible is controversial. There is no general agreement in the society that we should read more in the Bible. When nudging is about means and goals that most people can agree upon, paternalism may not be that problematic.

The second objection was that nudging is manipulative. When we buy more vegetables and fruits because these groceries are placed at the entry, most of us are not conscious that the shop has chosen this setup in order to influence our behaviour. As we said, this presupposes a hidden paternalism. But in addition, the rearrangement of the choice architecture plays with our brain. We are to a certain degree manipulated. This is problematic. We do not like to be deceived. We like transparency. And far worse, while buying more vegetable seems to be a rather innocent consequence of manipulation, there are of course regimes that want to use these techniques for bad purposes if they really influence our cognition [17]. Maybe we then need to be careful with introducing nudges if they are inherently manipulative?

There is clearly an element of behaviour manipulation involved in nudging. This is problematic from an ethics of health promotion, since the concept of health within this tradition is so clearly linked to enabling and empower people to improve their health. If we are solely manipulated to make better choices, the agency disappears-we do not seem to be in charge or in control of the choices we make.

There are however ways to defend nudging as an ethical health promoting strategy: First, peo- ple can be oriented about the changes of the choice architecture and why it is done. In that way, nudges become transparent. Second, Thaler and Sunstein stress that nudgers - those that are nudged - should be better off, judged by themselves [15]. People can also be included in decision processes about which products, actions and lifestyles that is best fitted for nudging. That takes away some of the paternalist critique and let nudges become democratic. Finally, we should remember that manipulation of our brain is something that the consumer industry has been doing through commercials for decades. Using nudging for public health promotion-for the common good-and not for private enrichment, serves a higher goal. With that reminder healthpromoting nudges might become legitimate and important.

\subsection{Health Promotion in Health Care Vs. Public Health}

When we shift the focus from health promotion in public health to health promotion in health care, all the goals we have been talking about are still valid. Enabling people to increase control over, and to improve, their health is of course of utmost importance. Furthermore, to be able to cope well for instance with a chronic disease would be central in health promotion in health care.

Still, there are some differences. The political dimension of public health is not that distinct within health care. What makes a difference within health care would be the doctor-patient relation, the nurse-patient relation as well as the systemic approach to continuous follow-up of patients. It is in the relational aspect of health care, then, that we find the key to the ethical dimension of health promotion in health care.

Some of the same ethical discussions that we find in public health, though, is also found within health care. One of them is the discussion on nudging that recent years also have entered the field of health care. Nudging in a clinical setting would mean that doctors rearrange the "choice architecture' in such a way that is more likely that the patient will make what the doctor consider as 
the right choice. In the anthology Nudging Health from 2016, arguments for and against clinical nudging are discussed thoroughly. Clinical nudging was also the subject for a special issue in the American Journal of Bioethics in 2013. Here Shlomo Cohen suggested that nudging in health care offers 'an important new paradigm' and has the potential to 'overcome the classical dilemma between paternalistic beneficence and respect for autonomy' [18].

I will not dive deep into this special discussion. But since I expressed a positive attitude to nudging as a tool for health promotion in public health, I should say something about my view on nudging in a clinical context. Nudging in a clinical setting, is in my view, far more ethical problematic than nudging in a public health setting. This is due to the manipulative and deceptive element of nudging. In the former discussion, I agreed that there is such a manipulative element. But I also gave reason for how this manipulative element can be reduced as well as legitimated. In a clinical setting, I agree with the criticism raised by Søren Holm that 'deceptive nudging in a personal relationship may undermine trust much more quickly than deceptive nudging from institutions that by definition are known to act strategically to pursue societal goals' [19]. What we are really interested in the clinical setting cannot be reduced to health, but rather the process of creating health, what Lindström and Eriksson have called healthy learning [20].

The risk of undermining trust by nudging 'the right choice' is one important criticism of clinical nudging. But almost equally important is the question whether we can talk of 'the right choice' in health care. Seen from a health promotion view, this is far more complicated. This takes us to some of the fundamental value discussions in health care today.

\subsection{The Shortcomings of an Ethics of Autonomy in Health Care}

For many decades, there has been focus on one prominent value in medical ethics and health care ethics in the western world-patient auton- omy. Already in the 1980s, a leading text book in medical ethics wrote that although '...the physician's primary obligation is to act for the patient's medical benefit (..) autonomy rights have become so influential that it is today difficult to find clear affirmations of traditional models' [21]. The focus on patient autonomy came as a reaction to medical paternalism and the attitude that the doctor always knows best for you. People and patients must be allowed to decide for themselves.

Why autonomy should be considered such an important value in health care is not obvious. Medical knowledge is an expert field where doctors and nurses usually know a lot more than their patients. Patients obviously need healing and caring, but not that obviously choices. While choices are of utmost importance in many fields of society, choices are any way only offered within a limited range in health care-your medical doctor always decide what treatments to choose between. Some critics have claimed that the presence of a choice does not in itself ensure empowerment of patients and that the whole focus on patient autonomy is delusional and does not reflect what is really at stake in health care settings' [22].

It is here that health promotion in health care enters the value field. Health promotion is not concerned with choices per se, but with health. However, with the underlying definition of health as salutogenesis, health promotion offers a comprehensive value system where also patient autonomy can find its proper place. Below we will explain how.

\subsection{Empowerment as the Basis for Health Promotion in Health Care}

Sense of coherence, meaning, is, as we noted earlier, a vital aspect of health promotion. As Eriksson and Lindström have pinpointed, sense of coherence is '.... an important disposition for people's development and maintenance of their health' [23]. For a patient to be able to benefit from a treatment, he must be able to see for instance how a certain lifestyle change or a fol- 
low-up make sense and can fit into her life. He must of course be informed about every aspect of the treatment, but equally important he must feel he is able to cope with the task, manage the disease and comprehend all aspects of the situation. To promote health in health care means enable patients to be in charge or in control of their patient role. Patients must be educated, but they must also be ascribed trust, optimism, hope and responsibility. Nurses and doctors must be interested in the patient's biography and social context, in order to contribute to the coping, the control and the sense of coherence. That entails an empathic and holistic approach to patients.

There is a single word for all of this, a word that is far more important in health care than autonomy. That word is empowerment. Health promotion in health care is genuinely about empowerment. From a focus on empowerment, many other values can easily be derived, values like holism, empathy, autonomy and user involvement. An ethics of health promotion in health care is genuinely an ethics of empowerment. What difference does it make if we shift the main ethical focus to empowerment instead of autonomy in health care?

Empowering patients and persons means to enable people to participate or perform in a certain practice or role. A patient can formally be declared autonomous, and she might also be offered choices, but if she is not able to transform the choices and the information into her own life project, then the term autonomy does not seem to do the job. Neither from the point of view of health personnel, does this term do the job: Nurses and doctors can be taught that their ethical duty is to respect patient autonomy, but what does that mean? Does it mean that nurses should encourage patients to have independent 'opinions' on the treatment offered? If so, why would that be an ethical ideal?

Empowerment, on the other hand, is a value that can do the job. Empowerment addresses the importance of agency - the importance of being a person or patient that as far as possible leads his life from the inside, copes with the hardships of his life and integrates medical events into a meaningful biographical story. Unlike autonomy, empowerment directly instructs nurses and doctors on what their ethical obligation towards patients are. In the words of Koelen and Lindström, the role of the professional '....is to support and provide options that enable people to make sound choices, to point to the key determinants of health, to make people aware of them and enable people to use them. In this enabling process it is important to help people to see a correspondence between their efforts and the outcomes thereof. It includes guiding clients through change processes in a successful way, that positively influences feelings of control' [24]. Doctors and nurses should do whatever they can to enable the patient to become this agent that can cope, master and feel coherence. And why should they do it? Because this is what health is about.

The fundamental ethical idea of salutogenesis could basically be formulated as a variant of the old slogan saying that it is not what happens to you, but how you react to it matters. A patient may have a severe disease, but his health could still be considered good if he considers his life meaningful, he is capable of coping with the disease, and he has some feeling of well-being. Promoting health in this sense should be the ultimate ethical goal of health care, because this goal would be valid independent of whether we talk about curative treatment, chronic diseases, palliation or end-of-life care. Exactly how health can be promoted through patient empowerment is not the topic of this chapter of the book. We have confined ourselves to a mild warning against nudging in health care in contrast to public health.

Having reached the conclusion that empowerment represents the ethical ideal for health promotion in health care, we can now look back on our discussions on public health ethics. Are there anything that suggest that empowerment is less relevant as an ethical ideal for health promotion outside health care? In my view, the answer is no. Even though some would suggest that the ultimate goal of a society would be to reduce the burden of disease, this would not be the most satisfying answer. Also, in public health, the ultimate goal should be to create a society where citizens can flourish, cope, realize their potential and aspirations, feel coherence and have a high 
degree of well-being. This is what health is about. And this is what health promotion should care about-either in health care or in public health.

\subsection{Conclusion}

Ethical issues in health promotion has often been discussed with regard to public health issues. In the same way as two fundamentally different concept of liberty defines the political debates in our societies, in the same way two corresponding concepts of health define the public health debates. Health promotion is premised on a positive concept of health, where the society and the community play a major part for individuals to realize their potential for living and leading a healthy life. Nudging is an ethically contested but also interesting tool for how to promote health in our society, but probably less valid within health care. An ethical reading of health promotion in health care tells us that one of the most fundamental values we should adhere to is empowerment. Empowerment guides health personnel in a very direct way towards their ethical mission. This concept should replace the focus on patient autonomy as the core value of western health care.

\section{Take Home Messages}

- There is an important ethical difference between a positive and a negative concept of health.

- Interfering in people's life in order to enable them to make better health choices judged by themselves is ethically justified.

- Nudging is a very interesting tool for health promotion in public health, but should be used with caution within health care, due to the deceptive aspect that may undermine trust in care relations.

- Empowering patient within health care or empowering citizens within public health, to better be able to cope, control, find meaning and reach well-being, seems to be the most superior ethical call and vision for health promotion.
- The prominent position of patient autonomy within health care should be replaced by the principle of empowerment-it better directs health personnel to their ethical task, and it better suits the ethical needs of patients.

\section{References}

1. The Ottawa charter for Health Promotion. First International Conference on Health Promotion, Ottawa, 21 November 1986 [Internet]. https://www. who.int/healthpromotion/conferences/previous/ ottawa/en/index1.html. Accessed 1 May 2020.

2. Carter SM, Cribb A, Allegrante JP. How to think about health promotion ethics. Public Health Rev. 2012;34(1):1.

3. Berlin I. Two concepts of liberty. In: Four essays on liberty. London: Oxford University Press; 1969. p. 118-72.

4. Taylor C. What's wrong with negative liberty. In: Philosophy and the human sciences-philosophical papers, vol. 2. Cambridge: Cambridge University Press; 1985. p. 211-29.

5. Antonovsky A. Health, stress and coping. San Francisco: Jossey-Bass; 1979.

6. Marmot M. Social determinants of health inequalities. Lancet. 2005;365(9464):1099-104.

7. Greenfield EA. Child abuse as a life-course social determinant of adult health. Maturitas. 2010;66(1):51-5.

8. Eriksson M. The sense of coherence in the Salutogenic model of health. In: Mittelmark MB, Sagy S, Eriksson $\mathrm{M}$, et al., editors. The handbook of Salutogenesis. Cham: Springer; 2017.

9. Gill TP, Boylan S. Public health messages: why are they ineffective and what can be done? Curr Obes Rep. 2012;1:50-8.

10. Lupton D. The pedagogy of disgust: the ethical, moral and political implications of using disgust in public health campaigns. Crit Public Health. 2015;25(1):4-14.

11. Jones MR, Barnoya J, Stranges S, Losonczy L, NavasAcien A. Cardiovascular events following smoke-free legislations: an updated systematic review and metaanalysis. Curr Environ Health Rep. 2014;1:239-49.

12. Faber T, Kumar A, Mackenbach J, Millett C, Basu S, Been J. Effect of tobacco control policies on perinatal and child health: a systematic review and metaanalysis. Lancet Public Health. 2017;2(9):e420-37.

13. Conley S. Coercive paternalism in health care: against freedom of choice. Publ Health Ethics. 2013;6(3):241-5.

14. Pugh J. Coercive paternalism and back-door perfectionism. J Med Ethics. 2014;40(5):350. 
15. Tahler R, Nudge SC. Improving decisions about health, wealth and happiness. New Haven: Yale University Press; 2008.

16. WHO Global Network for Age-friendly Cities and Communities [Internet]. https://www.who.int/ageing/ projects/age_friendly_cities_network/en/. Accessed 1 May 2020.

17. Wilkinson TM. Nudging and manipulation. Polit Stud. 2013;61:341-55.

18. Cohen S. Nudging and informed consent. Am J Bioeth. 2013;13(6):3-11.

19. Holm S. Context matters-why nudging in the clinical context is still different. Am J Bioeth. 2019;19(5):60-1.

20. Lindström B, Eriksson M. From health education to healthy learning: implementing salutogen- esis in educational science. Scand J Public Health. 2011;39(Suppl 6):85-92.

21. Beauchamp TL, Childress JF. Principles of bioethics, vol. 272. New York: Oxford University Press; 1989.

22. Agledahl KM, Førde R, Wifstad A. Choice is not the issue. The misrepresentation of healthcare in bioethical discourse. J Med Ethics. 2011;37:212-5.

23. Eriksson M, Lindström B. Antonovsky's sense of coherence scale and the relation with health: a systematic review. J Epidemiol Community Health. 2006;60:376-81.

24. Koelen MA, Lindström B. Making healthy choices easy choices: the role of empowerment. Eur J Clin Nutr. 2005;59(Suppl 1):S10-6.

Open Access This chapter is licensed under the terms of the Creative Commons Attribution 4.0 International License (http://creativecommons.org/licenses/by/4.0/), which permits use, sharing, adaptation, distribution and reproduction in any medium or format, as long as you give appropriate credit to the original author(s) and the source, provide a link to the Creative Commons license and indicate if changes were made.

The images or other third party material in this chapter are included in the chapter's Creative Commons license, unless indicated otherwise in a credit line to the material. If material is not included in the chapter's Creative Commons license and your intended use is not permitted by statutory regulation or exceeds the permitted use, you will need to obtain permission directly from the copyright holder. 